\title{
Continuing Controversies
}

\section{Contemporary Treatment of Chronic Lymphedema}

JOHN J. BERGAN, M.D., FACS, FRCS (HON.), ENG.

ABSTRACT Lymphedema presents as a recurring problem to vascular surgeons. Its primary cause is fundamentally unknown and modern treatment has not been emphasized in teaching programs, specialized courses or our national meetings.

Clinical findings, methods of verification of diagnosis, classification and summary of treatment options are the subject of this presentation. Disadvantages of pump therapy and advantages of specialized massage therapy are emphasized. A review of modern de-bulking procedures is provided and mention is made of the current status of direct microlymphatic reconstruction and pharmacologic therapy.

Keywords Lymphedema, pneumatic compression, manual lymphatic drainage, complex decongestive physiotherapy, lymphoscintigraphy

Lymphedema is frustrating to physician and patient alike. This is true because it is incurable and, despite intensive investigations, its cause is fundamentally unknown. The prime function of the lymphatic system is to clear the interstitial spaces of excess water, large molecules, and particulate matter. These are transported from the tissues back into the intravascular circulation. A large proportion of plasma proteins pass through the capillary wall daily and not all of these return directly to the circulation. The lymphatic system absorbs those protein molecules that fail to return to the circulation by way of veins. As much as a third of the proteins escaping from the blood are cleared by the

J.J.B., Professor of Surgery, University of California, San Diego, San Diego, CA; Clinical Professor of Surgery, Uniformed Services University of the Health Sciences, Bethesda, MD

Copyright (C) 2000 by Thieme Medical Publishers, Inc., 333 Seventh Avenue, New York, NY 10001, USA

Tel.: +1(212) 584-4662. 0894-8046,p;2000,13,2,43,54,ftx,en; pvs00096 
lymphatics. Failure of any part of the lymphatic system will result in accumulation of plasma proteins in interstitial fluid. This increases interstitial fluid colloid osmotic pressure and directs movement of water toward the interstitial space.

The clinical presentation of lymphedema may be at birth, sudden, or slowly developing later. Early edema is painless, begins on the dorsum of the foot and ankle, and progresses proximally. At first, it subsides during recumbency and worsens towards the end of the waking day. The swelling becomes permanent secondary to fibrosis of skin and subcutaneous tissue. When the edema involves the dorsum of the feet, the toes may be swollen also. Inability to pinch a skin fold at the base of the second toe is a diagnostic feature called the Kaposi-Stemmer sign (Fig. 1). In later stages, affected skin becomes thickened, darkened, and develops multiple warty projections. This is referred to as lymphostatic verrucosis. This article discusses the clinical classification of lymphedema, and its common treatments, such as sequential compression, physical therapy, massage therapy, and pharmacologic treatment. Also covered will be the surgical treatment of lymphedema, as well as proven reconstructive techniques.

Although lymphedema is a clinical diagnosis, objective verification is often desirable. Lymphoscintigraphy provides objective diagnosis and describes the anatomy of the lymph vessels and the dynamics of lymph flow. It is not quantitative. Characteristic findings in lymphedema suggest an obstructive flow pattern, especially in patients who have had cellulitis. This suggests that recur-

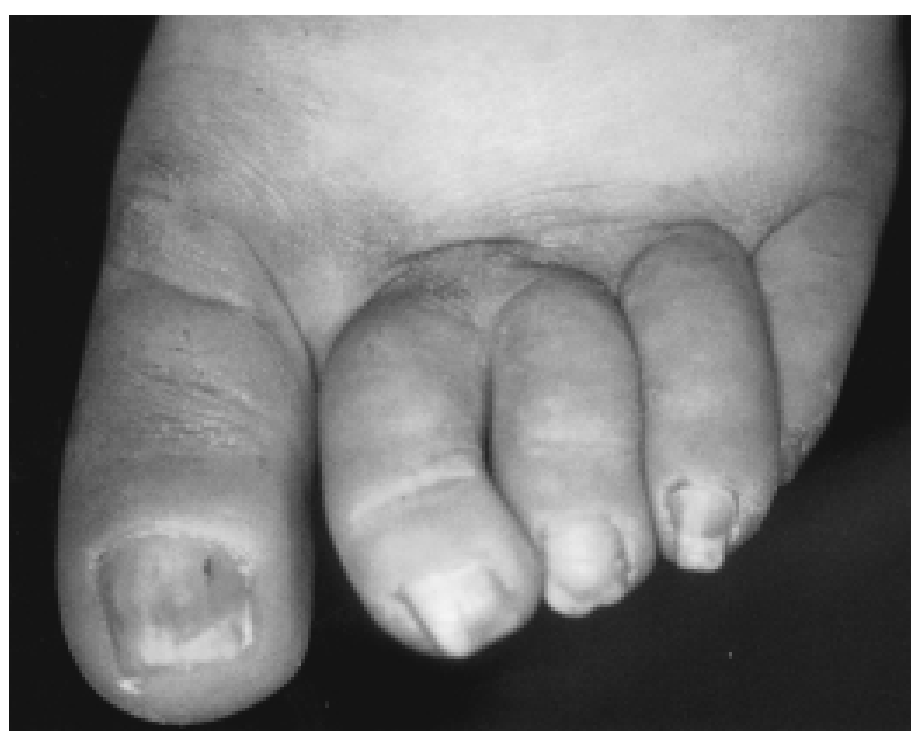

Fig. 1 Inability to pinch the second toe skinfold, Stemmer sign, is useful in diagnosis of lymphedema. 
rent cellulitis causes progression of the lymphedema, an implication which strongly influences prophylaxis of infection during edema reduction therapy. A simple but accepted classification of lymphedema is shown in Table 1.

\section{TREATMENT OF LYMPHEDEMA}

While a variety of interventional techniques have been tried in treatment of lymphedema, in fact the cornerstone of therapy is supportive. This consists largely of compression therapy. Within compression therapy, two treatment phases can be separated. First is the therapy phase which reduces the size of the limb. Second, there is a maintenance phase in which the limb is maintained in its decreased size. A summary of treatments of lymphedema is displayed in Table 2.

As indicated by the imaging studies, lymphedematous limbs are characterized by marked increase in thickness of the subcutaneous tissue components. This subcutaneous tissue exists in three forms. Two are fluid phases and the third is a solid tissue phase. Fluid exists as interstitial free fluid and a bound interstitial polysaccharide form in which fluid is bound to hyaluronic acid and entangled within a network of collagen and elastin fibers. ${ }^{2}$ It is the interstitial fluid phase which moves freely and is most influenced by external compression. ${ }^{3}$

The effects of compression on lymphatic microcirculation as well as other changes produced by compression on tissues are very complex. Some mechanisms have only recently been elucidated. Edema reduction is thought to be caused by shifting Starling's equilibrium towards a decrease in filtration and an increase in absorption. However, compression decreases the water content of the leg more than the protein volume so that oncotic tissue pressure actually increases. ${ }^{4}$ From a practical standpoint, this means that edema will recur if maintenance compression is not used. ${ }^{5}$ Deep subfascial lymph transport is enhanced by compression therapy. This has been shown by isotope lymphography. ${ }^{6}$ External compression combined with physical activity provides a physiologic stimulus for lymph propulsion by the actions of adjacent arterial pulsations and muscular compression. ${ }^{7}$

Table 1 Clinical Classification of Lymphedema ${ }^{1}$

\begin{tabular}{ll}
\hline Grade 1 & $\begin{array}{l}\text { Pitting edema } \\
\text { Subsides on elevation }\end{array}$ \\
\hline Grade 2 & Skin thickening \\
& Edema pits slowly \\
& Moderate reduction on elevation \\
\hline Grade 3 & $\begin{array}{l}\text { Marked skin thickening } \\
\text { Little pitting on pressure } \\
\text { Minimal benefit by elevation }\end{array}$ \\
\hline
\end{tabular}


Table 2 Treatment of Lymphedema*

\begin{tabular}{ll}
\hline Process & Effect \\
\hline Exercise & $\begin{array}{l}\text { Dynamic muscle contractions encourage passive move- } \\
\text { ment of lymph along tissue planes and noncontractile } \\
\text { lymph vessels and increased contractility of collecting } \\
\text { lymph vessels }\end{array}$ \\
\hline Compression stockings & $\begin{array}{l}\text { Opposes capillary filtration } \\
\text { Acts as a counterforce to muscle contractions }\end{array}$ \\
\hline Manual lymphatic drainage & $\begin{array}{l}\text { Massage stimulates lymph flow in more proximal lym- } \\
\text { phatics to siphon lymph from congested areas }\end{array}$ \\
\hline Multilayer bandaging & $\begin{array}{l}\text { Used in combination with exercise to reduce large, mis- } \\
\text { shapen limbs to permit maintenance treatment with } \\
\text { stockings }\end{array}$ \\
\hline Pneumatic compression & $\begin{array}{l}\text { Softens and reduces limb volume but can forcibly dis- } \\
\text { place fluid into trunk and genitalia }\end{array}$ \\
\hline Elevation & $\begin{array}{l}\text { Does not stimulate lymph drainage but lowers venous } \\
\text { pressure }\end{array}$
\end{tabular}

* Modified from Ko DS, Lerner R, Klose G, Cosimi AB. Effective treatment of lymphedema of the extremities. Arch Surg 1998; 133:452-58.

Edema reduction also occurs because of an increase in cutaneous blood flow $^{4}$ and this, in turn, depends upon the amount of resting pressure of an external bandage. Elastic bandages cause high pressure on the skin and subcutaneous tissues of a limb even in the recumbent position, thus decreasing arterial perfusion. On the other hand, semi-rigid or nonelastic bandages exert a lesser resting pressure and are better tolerated. Inelastic material used as a support with extremely mild resting pressures can reduce edema if ankle movement is reinforced. Deep subfascial lymph transport is improved by the external compression and physiologic movement. ${ }^{6}$ Lymph propulsion is accelerated by the action of arterial pulsation and the adjacent muscular contraction. ${ }^{7}$

Hargens has compared the effects of a nonelastic compression system to gradient elastic stockings with 30 to $40 \mathrm{mmHg}$ ankle pressure. ${ }^{8}$ Surface compression was recorded as well as intramuscular pressures. In the supine position, the elastic compression system produced higher surface pressures as well as an increased intramuscular pressure. The nonelastic system at rest produced low surface and low intramuscular pressure. During walking and running, surface and intramuscular pressures generated by the nonelastic system were higher than those generated in the elastic compression system. This suggests 
better function of nonelastic systems in treatment of lymphedema because of lack of external pressure at rest and higher internal pressures during exercise. ${ }^{9}$

The non-elastic system which was used by Hargens is marketed under the commercial name CircAid (CircAid Medical Products, Inc., San Diego, CA) (Fig. 2). This device consists of a number of pliable, non-stretch, adjustable compression bands which are fitted from the instep to the knee. These are closed with Velcro fastening and may be tightened as limb size reduction is achieved. ${ }^{10}$ Nursing experience has shown that this device is optimal for arthritic, obese, or elderly patients who find it difficult to apply elastic stockings. A single drawback to this device is its appearance, as it is quite bulky and difficult to hide, except under trousers. ${ }^{11}$

\section{Sequential Compression}

While conservative measures such as maintenance of skin nutrition, eradication of bacterial and fungal infection, and external compression are effective for mild lymphedema, more extensive lymphedema requires further therapy. This can be achieved with intermittent external pneumatic com-

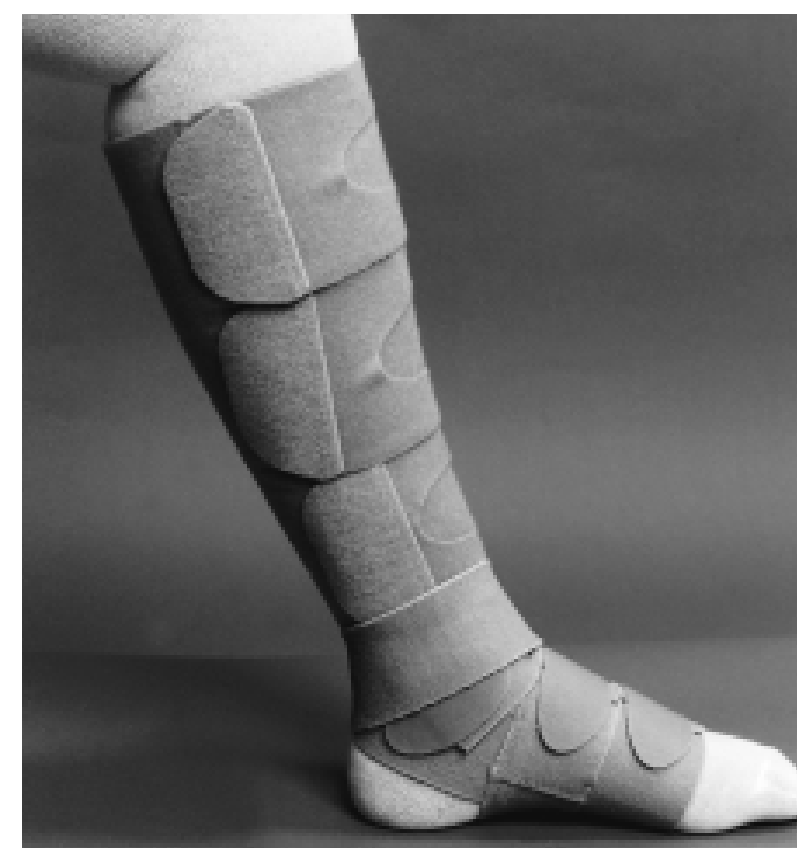

Fig. 2 The CircAid device which consists of overlapping Velcro strips was designed specifically for the control of lymphedema. It can be used without sequential pneumatic pumping, and is quite effective. When used with sequential pneumatic pumping, control of lymphedema is achieved and complications prevented. 
pression. Experience with a single compartment sequential pneumatic compression system demonstrates the possibility of reducing edema in lymphedematous limbs. ${ }^{12}$ Subsequently, multicompartment, high pressure pneumatic compression devices have been developed. ${ }^{13}$ These have a distaltoproximal milking action using multiple cells. They do mobilize large volumes of edema fluid. Experience has shown that the high pressure compression does not cause cutaneous, neurologic, lymphatic, or muscular damage. The beneficial effects of compression are more rapidly achieved with higher pressures. ${ }^{14}$

One of the earliest multiple cell devices marketed in the United States is the LymphaPress (Camp Medical Products, 1-800-492-1088). In this device, a distributor pump fills each cell separately, beginning with the first distal cell. Successive inflation creates a centripetal distaltoproximal milking action. Once the entire sleeve or legging is filled, all of the cells empty automatically and simultaneously. Ordinarily, the compression period is $24 \mathrm{sec}-$ onds on the first cell and only two seconds on the last, with the entire cycle, including a rest interval, being 30 seconds.

Objective measurement of the efficacy of various treatments has been difficult to obtain. A number of devices have been used in this attempt. However, the most recent has been use of computed tomography (CT) added to clinical measurements. Using these, intermittent pneumatic compression treatment has shown to decrease edema from $23 \%$ to $15 \%$ as measured by CT, compared to $23.5 \%$ to $13.2 \%$ clinical measurement. Density of muscle tissue increased $9 \%$ while that of subcutaneous tissue decreased $5.6 \% .^{15}$

As experience with the pneumatic pumps increased, so did disappointment with their results. Rapid return of limb swelling once the affected limb was out of the therapeutic sleeve was the rule. As the European experience with massage therapy came to America, an explanation for this became obvious. Manual lymphatic drainage, the basis for the techniques popularized by the Földis, decongests the trunk first, the proximal swollen limb next, and the distal part of the limb last (Fig. 3). Use of the pneumatic pump disregards the fact that the ipsilateral trunk quadrant remains congested. The pump attempts to force fluid from the congested limb into a congested trunk. Also, in treatment of lower extremity lymphedema with sequential pneumatic compression, genital lymphedema developed in some cases. This produced a true therapeutic tragedy, remedial only by surgical debulking.

\section{Physical Therapy}

Massage therapy was used in treatment of lymphedema as early as 1882 and was improved during the 1930s. ${ }^{16}$ These treatments were effective but maintenance was not practiced because of the lack of compression bandages and garments. Massage therapy was markedly improved and more organized using the techniques of Földi in Europe and CasleySmith in Australia. 17,18 


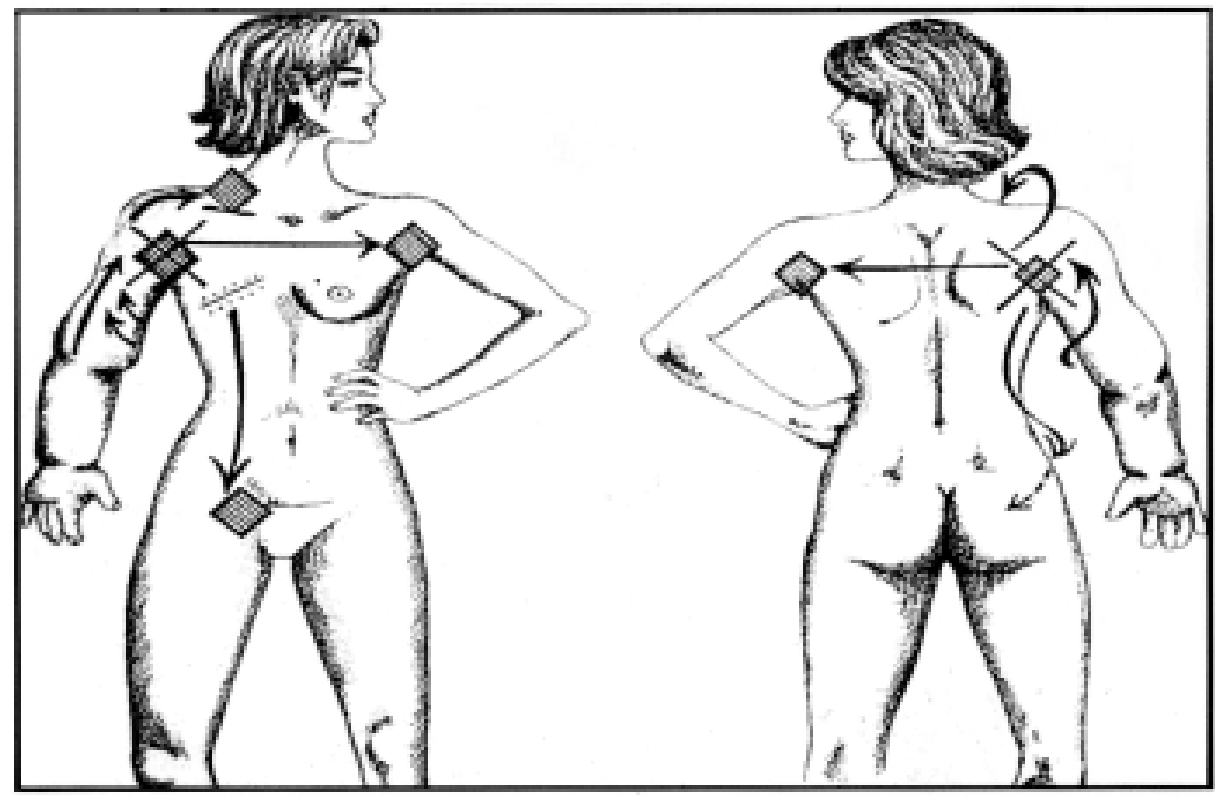

Fig. 3 This diagram illustrates the principle of manual lymphatic drainage. Proximal lymphatic basins are emptied prior to moving fluid from the lymphedematous limb to the trunk

These massage therapies, in essence, maximized central lymphatic drainage by first opening collateral vessels and then massaging the peripheral lymphedematous area to drain into the normally functioning lymphotomes. Rapid reduction in lymphedema has been achieved by these techniques.

A recent report on this subject in the United States describes the virtues of massage therapy. ${ }^{19}$ But, as has been true of other studies on the subject of treatment of lymphedema, claims are broadly made and controlled studies and measurements are lacking. For example, massage therapy combined with nonelastic bandaging was not separated into its components. It may be that the component of non-elastic bandaging is effective alone. Experience with the CircAid support in treatment of lymphedema suggests that it is the nonelastic compression which is effecting edema reduction rather than massage therapy.

\section{Massage Therapy}

There is no cure for lymphedema. There is no obviously effective pharmacotherapy. For a majority of patients, the best care is given by adopting the specialized lymphedema massage techniques that originated in Europe. ${ }^{20}$ These came to America with a variety of terms, which then became modified 
to avoid "turf battles." These terms include manual lymphatic drainage (MLD), complete decongestive physiotherapy (CDP), complex decongestive physiotherapy (CDP), and complete decongestive therapy (CPT). The principles involved in the application of these techniques were identical even though the individual procedures varied and were aggressively defended by the schools which taught them.

The principles include:

1. Skin and nail care to totally eradicate any possibility of bacterial or mycotic infection

2. Manual lymphatic drainage

3. Compression therapy

4. decongestive exercises

The technique of manual lymphatic drainage has nothing in common with classical or even Swedish massage. In fact, the term massage, which means to knead, is not used. MLD is a gentle treatment delivered by hand and is essentially a light touch designed to stretch the subpapillary lymph collectors, thus better filling lymph capillaries and transporting lymph in a proximal direction.

The first step in MLD is to stimulate the nonaffected lymph vessels in the contralateral quadrant of the trunk; that is, the unaffected side. This exerts a suction effect on the affected quadrant and extremity, which can be observed as a peau d'orange appearance of the skin. The next step is to apply the same gentle and stimulating manipulations to the affected area beginning proximally to empty the initial lymphatics and lymph vessels from congested tissues into the quadrant free of edema. After the trunk is decongested, the proximal part of the extremity and the distal part are decongested, leaving the affected hand or foot to the last.

Following MLD, it is mandatory to apply sufficient compression to prevent reaccumulation of fluid. For this purpose, short-stretch bandages are used. These exert little pressure when the extremity is relaxed and horizontal and maximum working pressure when the extremity is in use and dependent. The objective of compression is to decrease ultrafiltration, improve reabsorption, improve filling of initial lymph vessels, and amplify the emptying effect of the muscle pump. Although this is referred to as elastic compression, in practice the net effect is probably identical to the non-elastic or non-stretch CircAid, which has an identical effect and identical objective. Therapy with the CircAid may be less costly if bandage costs and time of application are factored in.

\section{Surgical Treatment of Lymphedema}

In essence, surgical treatment of lymphedema divides itself into debulking procedures and those which attempt to restore normal lymphatic drainage by 
reconstruction of lymphatic trunks. No surgical procedure has achieved the goals of simplicity, safety, reliability, reproducibility, and improvement of physiology. Techniques which have survived include those of Homans and Thompson. ${ }^{21,22}$ Homans described staged subcutaneous excision under thin skin flaps, and Thompson debulked the limb in a similar fashion but also provided a buried dermis flap that would serve as a conduit between the superficial, nonfunctional lymphatic system and the deep muscular system which was undamaged. Ultimately, both of these debulking procedures produced the same results-immediate decompression of the limb with later return of lymphedema.

Debulking of the limb by suction curettage, or lipectomy and liposuction has been done in modern times, but failure of rigid protocols of postoperative care discouraged general use of these procedures. ${ }^{23,24}$ Nevertheless, Brorson working in Malmö, has produced some tantalizing results with this technique. ${ }^{25}$ Initially, 28 patients were prospectively matched into two groups. One group received liposuction combined with controlled compression therapy (MLD) and one group received MLD therapy alone. The therapy group was then compared with a previous group of patients treated with liposuction combined with MLD therapy.

Using matched pairs (normal $=14$ ), the study showed that liposuction combined with MLD was significantly more effective than the MLD therapy alone $(\mathrm{p}<0.0001)$ with a mean difference of about $1000 \mathrm{ml}$ during a oneyear observation period. The beneficial effect of liposuction was confirmed by the comparison between the MLD therapy group and the complete group of patients treated with liposuction combined with therapy. The edema reduction figures after one year were $47 \%$ and $104 \%$, respectively $(\mathrm{p}<0.0001)$. In six patients who had surgery and a complete reduction of the edema, the compression garments were removed for one week, one year postoperatively. A marked increase in arm volume was observed, which was immediately remedied by reapplying the garments. Liposuction combined with controlled compression therapy reduced arm lymphedema more efficiently than the MLD therapy alone. Continued use of compression garments was important in maintaining the primary surgical outcome.

\section{Reconstructive Techniques}

Treatment of lymphedema by microsurgical lymphatic anastomoses has proven attractive to the surgical mind. Under the microscope, grafts are anastomosed directly. For example, in unilateral blockade at the groin or pelvis, free grafts can connect lymphatics of the thigh to proximal, nonobstructed lymphatics. ${ }^{26}$ Otherwise, direct lymphatic anastomoses to the venous system have been proposed. ${ }^{27}$ In these techniques, volume measurements and lymphatic scanning has shown some patency, improvement of transport time, and reduction in limb volumes. Nevertheless, these techniques have not emerged to become either commonplace or routine in 
lymphedema management. In O'Brien's unit in Melbourne, 19 patients ultimately treated by liposuction, contained a group of 12 who had previously been treated with microlymphaticovenous anastomoses or surgical reduction, suggesting that neither of those techniques had a longterm beneficial effect. ${ }^{28}$

\section{Pharmacologic Treatment of Lymphedema}

The 1993 publication by CasleySmith in the New England Journal of Medicine provoked a great deal of interest in pharmacologic treatment of lymphedema. ${ }^{29}$ In that publication in a very prestigious journal, data seemed to show that the 5,6-benzo- $[\alpha]$-pyrone effectively reduced the volume of lymphedema. It was said that the improvement was "statistically significant and clinically meaningful." Because these agents can be obtained in this country even without FDA approval by a variety of methods, they have gradually crept into use.

It is said by proponents that these benzopyrones reduce volume of highprotein edema by increasing proteolysis and uptake by microphages. Because the effects of benzopyrones are very slow and may take many months to become obvious, it has been suggested that these be combined with massage therapy as a compliment to other conservative therapy. Controlled studies on the use of these agents are requisite, as none have been performed and the beneficial effect of these agents has not been conclusively proven.

\section{REFERENCES}

1. Bruna J, Miller AJ, Beninson J. Clinical classification of lymphedema. Eur J Plastic Surg 1999;22:404-405

2. Nehler MR, Moneta GL, Woodard DM, De Frang RD, Harkes CT, Taylor LM Jr, Porter JM. Perimalleolar subcutaneous tissue pressure effects of elastic compression stockings. J Vasc Surg 1993;18:783-788

3. Jackson GW, James DF. The hydrodynamic resistance to hyaluronic acid and its contribution to tissue permeability. Biorheology 1982;19:317-330

4. Partsch H. Compression therapy of the legs: a review. J Dermatol Surg Oncol 1991; 17:799-805

5. Partsch H, Mostbeck A, Leitner G. Experimentelle untersuchungen zur Wirkung einer Druckwellenmassage (Lymphapress) belm Lymphödem. Phlebol Proktol 1980;9: 124-128

6. Haid H, Lofferer O, Mostbeck A, Partsch H. Die lymphkinetik beim postthrombotischen syndrom unter kompressionsverbänden. Med Klin 1968;63:754-757

7. McGeown JG, McHale NG, Thornbury KD. The role of external compression and of movement in lymph propulsion in the sheep hind limb. J Physiol 1987;387:83-93

8. Murthy G, Ballard RE, Breit GA, Watenpaugh DE, Hargens AR. Intramuscular pressures beneath elastic and inelastic leggings. Ann Vasc Surg 1994;8:543-548

9. Bergan JJ, Sparks SR. Nonelastic compression: an alternative in the management of chronic venous insufficiency. J Wound Ostomy Nurs 2000;27:83-89 
10. Vernick SH, Shapiro D, Shaw DF. Legging orthosis for venous and lymphatic insufficiency. Arch Phys Med Rehabil 1987;68:459-461

11. Cahall E, Spence R. Nursing management of venous ulceration. J Vasc Nursing 1994; $12: 48-56$

12. Raines JK, O’Donnell TF, Kalisher L, et al. Selection of patients with lymphedema for compression therapy. Am J Surg 1977;133:430-437

13. Zelikovski A, Melamed I, Kott M, et al. The "Lympha-Press": a new pneumatic device for the treatment of lymphedema: clinical trial and results. Folia Angiol 1980;28:165-169

14. Richmand DM, O'Donnell TF, Zelikovski A. Sequential pneumatic compression for lymphedema. Arch Surg 1985;120:1116-1119

15. Airaksinen O, Partanen K, Kolari PJ, Soimakallio S. Intermittent pneumatic compression therapy in posttraumatic lower limb edema: computer tomography and clinical measurements. Arch Phys Med Rehabil 1991;72:667-670

16. Von Winiwarter A. Chirurgischen krankheiten der haut. In: Deutsche Chirurgie. Stuttgart, Germany: Enke; 1892

17. Földi E, Földi M, Weissletter H. Conservative treatment of lymphedema of the limbs. Angiology 1985;36:171-180

18. CasleySmith JR, CasleySmith JR. Lymphoedema. Adelaide, Australia: The Lymphedema Association of Australia; 1991

19. Boris M. Weindorf S, Lasinski B, Boris G. Lymphedema reduction by noninvasive complex lymphedema therapy. Oncology 1994;8:95-106

20. Ko DS, Lerner R, Klose G, Cosimi AB. Effective treatment of lymphedema of the extremities. Arch Surg 1998;133:452-458

21. Homans J. The treatment of elephantiasis of the legs: a preliminary report. N Engl J Med 1936;215:1099-1110

22. Thompson N. Surgical treatment of chronic lymphedema of the lower limb. Br Med J $1962 ; 2: 1566-1571$

23. Sando WC, Nahai F. Suction lipectomy in the management of limb lymphedema. Clin Plast Surg 1989;16:369-373

24. Louton RB, Terranova WA. The use of suction curettage as adjunct to the management of lymphedema. Ann Plast Surg 1989;22:354-357

25. Brorson H, Svensson H. Liposuction combined with controlled compression therapy reduces arm lymphedema more effectively than controlled compression therapy alone. Plast Reconstr Surg 1998;102:1058-1068

26. Baumeister RG, Siuda S. Treatment of lymphedema by microsurgical lymphatic grafting: what is proved? Plast Reconst Surg 1990;85:64-74

27. Gloviczki P, Hollier LH, Nora FE, Kaye MP. The natural history of microsurgical lymphovenous anastomoses: an experimental study. J Vasc Surg 1986;4:148-156

28. O'Brien BMcC, Khazanchi RK, Kumar PAV, Dvir E, Pederson WC. Liposuction in the treatment of lymphoedema: a preliminary report. Br J Plast Surg 1989;42:530-533

29. CasleySmith JR, Morgan RG, Piller NB. Treatment of lymphedema of the arms and legs with 5,6-benzo-[ $\alpha]$-pyrone. N Engl J Med 1993;329:1158-1163 
